Chapter 17

\title{
AGRICULTURAL INSURANCE FOR DEVELOPMENT: PAST, PRESENT, AND FUTURE
}

\section{Miguel Robles}

Agricultural production is a risky activity subject to several contingencies that make farming incomes unstable and unpredictable from year to year. Bakst, Sewell, and Wright (2016) report that the Economic Research Service of the US Department of Agriculture (USDA) identifies five types of farming risk: (1) human and personal risk (such as human health), (2) institutional risk (regarding governmental action), (3) financial risk (such as access to capital), (4) price or market risk, and (5) production risk (such as weather and pests). The HIV/AIDS pandemic in African countries in the early 2000s is an example of a human risk that affected agricultural output and labor supply and demand. Land expropriation, land reforms, and unanticipated changes in the agricultural tax system are examples of institutional risk that can depress investment in the agricultural sector. Nonavailability of funds in the formal or informal financial sector or high interest rates reflecting liquidity scarcity at the beginning of the crop season can limit area planted in a year. Uncertain crop prices at harvest time and input prices during the crop calendar can have severe impacts on farm income and become a social problem when affecting many farmers.

Agricultural production is directly tied to weather variables such as rainfall, temperature, humidity, and wind. When extreme weather conditions occur, agricultural production typically suffers and, in some cases, may be lost completely. Year after year, unexpected weather extremes are a constant threat in several regions of the world, with devastating effects on agricultural production and rural livelihoods. Some examples of risky events happening within a short period of time globally are prolonged droughts in the Horn of Africa and the midwestern part of the United States, extensive floods in the Philippines and northern India, abnormally low temperatures in Japan and the United States, and heat waves in Australia and Europe. Also, extreme weather events allow pests and diseases to flourish, with potential large impacts over vast regions. 
According to Hazell and Hess (2016), risks can be characterized according to the following elements:

- Covariance. The degree to which they are correlated across households within a community or region, ranging from independent (affecting one person) to highly covariate (affecting everyone at the same time).

- Frequency. How often they occur.

- Types and severity of losses incurred. Shortfalls in seasonal production and income, damage to assets, and loss of life.

Table 17.1 expands on each of these elements and provides examples. The 2002 drought in Ethiopia that affected most of the country and led to 12.5 million people requiring food aid is an example of a highly covariate risk that generally occurs with low frequency but with catastrophic impacts within affected regions. Deaths and illnesses of people in individual households or livestock are risks that are weakly if at all covariate but that occur with high frequency. In a year it is not possible to predict which individual household will be impacted, but the proportion of total households affected each year is often predictable. Other risks are moderately covariate and occur with moderate frequency. These include losses in production and income or damage to assets due to less severe drought, excess rainfall, or market and price risks. When lost farm output at the local level is considerable and the degree of economic integration with other regions is low, then the rural nonfarm economy might suffer as well. This is because the local demand for other goods and services might also decrease substantially and widespread defaults on loans might happen as well, undermining the local rural financial systems.

Arias and Covarrubias (2006) classify agricultural risks as natural hazards and human-made risks and as risks that are within or beyond the control of the farmer (for instance, natural catastrophes or international financial crises). An example of a controllable risk is variations in river water flows by building proper irrigation and dam systems. Some risks are controllable to a certain extent, such as the effects of some plagues and diseases. This is an important distinction when studying crop insurance and designing policies, as access to insurance instruments should complement rather than substitute for best agricultural practices, especially those that help reduce controllable risks. Kyle et al. (2016) present evidence that introducing to Indian farmers a new rice variety that reduces downside risk has the potential to increase agricultural productivity in normal years. Insurance mechanisms should encourage this type of investment and be designed to take care of residual or noncontrollable risks. 


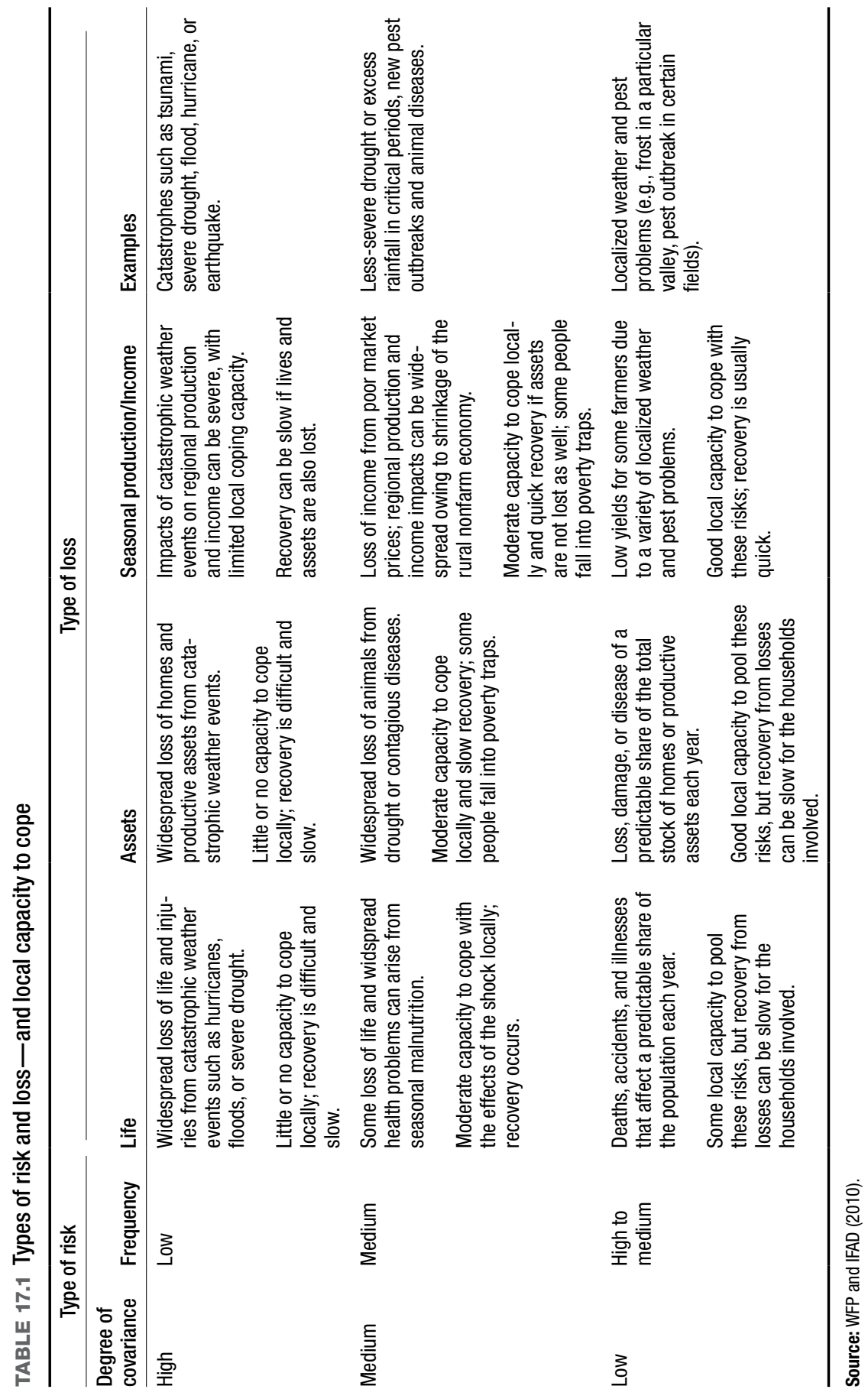


The severity of agricultural risks can be very high with catastrophic consequences. Hazell and Hess (2016) document the extent of events and losses due to natural disasters by region. They show that more than 7,000 natural disasters occurred between 1995 and 2015 worldwide, affecting a total of 4.3 billion people with damages estimated at US\$2.3 trillion. In Africa, 1,145 natural disasters-including droughts, extreme temperatures, floods, storms, wildfire, earthquakes, tsunamis, mass movements, volcanic activity, and landslides-occurred in this period with 308 million people affected. In Asia, 2,977 natural disasters affected 3.8 billion people. In Latin America and the Caribbean, 1,268 natural disasters occurred with total damage of US $\$ 158$ billion and 146 million people affected.

There are different options to manage agricultural risks, agricultural insurance being one of them. Actions taken before the risk materializes are known as ex-ante measures and actions taken after the fact as ex-post. Three main approaches can be used: risk reduction (ex-ante); risk mitigation (ex-ante); and risk coping (ex-post).

1. Risk reduction can occur in several ways: investments in hazard-resistant technology, such as irrigation systems and pest-resistant seed varieties, and through the diversification of income sources including off-farm employment and migration away from hazardous areas.

2. Risk-mitigation activities include crop insurance and saving. While saving is a risk-retention strategy, crop insurance is a risk-transfer strategy. In the former, the amount of savings must be large enough to be prepared for worst case scenarios either through own savings or by taking savings from others (credit). In the latter, only a fraction (typically a small fraction) of the potential losses are paid as a premium to secure the right to be compensated if a risk materializes; if the risk doesn't materialize, the premium is lost.

3. Risk-coping strategies when uninsured shocks hit include selling productive assets such as land and livestock, cutting back on consumption, and reducing investments in education among others.

\section{Traditional Crop Insurance in Developed Economies}

A key feature of a good agricultural insurance product is that it will compensate the farmers for losses that come after any negative event for the risks 
insured. Also, the insurance product should not induce inefficient production or behavioral decisions (to avoid moral hazard) and should let the insurance company discriminate between high-risk and low-risk clients (to avoid adverse selection). This is the case for any insurance market including agricultural insurance. Ideally when a farmer acquires agricultural insurance, he or she pays a premium. If a negative event occurs, for a risk that has been insured, which induces a loss in his agricultural income, he expects a compensation from the insurance provider equal to the size of the loss. In this sense agricultural insurance follows a similar logic to standard car or fire insurance. The insured customer pays a premium to the insurance company expecting to be compensated when a negative event coming from an insured risk triggers a loss. Standard insurance contracts are also denominated "indemnity" insurance since the client is "indemnified" by the insurance provider after verifying the size of the loss that is attributed to an insured risk. The size of the indemnity is in line with the size of the evaluated loss.

In practice, traditional agricultural insurance consists of multiple-peril or single-peril insurance instruments that require an insurance adjustor to physically verify assets (ex-ante) and losses (ex-post) on an individual farm basis. Under single-peril insurance, indemnities are paid for losses incurred for a single risk, such as hail. Under multiple-peril insurance, indemnities are paid for losses incurred from a broad range of risks. The World Bank (2005) provides an overview of agricultural insurance programs in the United States and Canada. These countries have been able to implement substantial programs aimed to reduce yield and revenue risk for agricultural producers. Although these programs offer a variety of risk-management products for farmers, in all cases programs require sizable levels of government support.

In the United States multiple-peril yield and revenue insurance products are offered through the Federal Crop Insurance Program (FCIP), a publicprivate partnership between the federal government and various private-sector insurance companies. A comprehensive review of how the FCIP expanded during the 1990s and first decade of the 2000s can be found in Glauber (2013). A key milestone is that under the Federal Crop Insurance Act of 1980, the Federal Crop Insurance Corporation was encouraged to privatize delivery functions to the maximum extent possible and to promote a rapid expansion. Currently the program is delivered entirely by private crop insurance companies and independent insurance agents (Glauber 2016).

By 2015 area insured under the program totaled almost 300 million acres, accounting for more than 85 percent of potentially insurable area and total liability (coverage in force) topped US $\$ 100$ billion. Crop insurance is viewed 
as a key piece of the federal farm safety net, and its annual costs have grown significantly since 2000 . Estimated annual costs are projected at $\$ 8.9$ billion over fiscal years 2016-2025, making it the largest single farm program in the farm safety net. By contrast, price and income support programs are estimated to cost $\$ 5.6$ billion annually, while conservation programs are estimated at $\$ 5.8$ billion over the same period. In the case of US federal crop insurance, producers are charged premiums that reflect the underlying actuarial risks of crop production (and revenue), and the same rates apply to all companies (no price competition). The government provides separate reimbursements for administrative and operating expenses. Also, insurance companies must take all eligible participants regardless of risk profile, not being allowed to turn down customers or adjust rates.

In Canada, since 2003, there are two main schemes: production insurance and income stabilization. The production insurance (PI) scheme offers producers a variety of multiple-peril production or production value loss products like many of those offered in the United States. One major distinction, however, is that the Canadian program is marketed, delivered, and serviced entirely and jointly by federal and provincial government entities, and Canadian producers are not allowed to separately insure different parcels but rather must insure together all parcels of a given crop type. Combined, the federal and provincial governments cover approximately 66 percent of program costs, including administrative costs. Beginning in 2004, the Canadian Agricultural Income Stabilization (CAIS) scheme replaced and integrated former income-stabilization programs. The program generates a payment when a producer's current year production margin falls below that producer's reference margin (based on an average of the program's previous five-year margins, less the highest and lowest).

It is important to emphasize that most, if not all, traditional multiple-peril crop insurance programs in developed countries, as well as in developing countries, require substantial government support. Goodwin and Smith (1995) concluded that purely private markets for traditional crop insurance are not feasible because agricultural insurance provision is too costly. This would make commercial unsubsidized premiums high enough to discourage the demand for insurance among farmers. They argue that large informational problems (moral hazard and adverse selection) are the reason why the provision of crop insurance is too costly. ${ }^{1}$

1 Moral hazard occurs when insurance clients take riskier actions once insured while insurance companies cannot perfectly observe such actions, leading to higher indemnity payments than 
One can ask why other insurance markets, such as car and home insurance, seem to work fairly well. One hypothesis is that information problems can be managed at a lower cost when insuring assets (cars, homes, equipment) than income (crop yields, unemployment), although we are not aware of rigorous research supporting this claim. In fact, Goodwin and Smith (1995) identify perils such as fire and hail for which private crop insurance do exist, although participation is small. One reason why such private markets are possible would be because measurement of such risks appears to be more straightforward, lowering monitoring and loss assessment costs. An open question for future research is whether new remote-sensing technologies could lower those costs, increasing the chance for commercially viable private crop insurance markets.

\section{Insurance Opportunities for Small-Scale Farmers: Index-Based Insurance}

In high-income countries farmers have access to and commonly use insurance and other financial products (for example, futures and options and credit) to protect themselves from shocks. Indemnity insurance products are available, although largely subsidized and supported by public funds. Access to these types of formal financial risk management products is essentially nonexistent in developing countries. Without formal insurance mechanisms, small-scale farmers in developing countries employ ex-ante risk-mitigation strategies such as relying on low-risk/low-yield production techniques, which can have negative livelihood consequences in the long run. Rosenzweig and Binswanger (1993) found that smaller and poorer farmers in a semi-arid region in India sacrificed 27 percent of their expected income to reduce risk. Similar results have been analyzed by others (Carter 1997; Morduch 1995).

In contrast, using a natural experiment among Chinese tobacco farmers, Cai (2016) shows that provision of agricultural insurance increases the insured crop production by 16 percent. Cole, Giné, and Vickery (2017) find that insurance provision induces farmers to invest more in higher-return but rainfall-sensitive cash crops. Jensen and Barrett (2017) document that when shocks such as droughts do occur, households might rely on detrimental

otherwise without insurance. "Adverse selection" describes a situation where a farmer's demand for insurance is positively correlated with his likelihood of crop (or income) loss while the insurance company doesn't have perfect information on that likelihood of loss. Farmers with high risk of crop loss will likely purchase insurance in larger amounts than farmers with low risk of loss, leading to higher aggregate indemnity payments that make insurance companies raise their premiums. This would discourage low-risk farmers even more from buying insurance, which ends up limiting the insurance market. 
coping strategies that include selling off productive capital, skipping meals, and withdrawing children from school (Hoddinott 2006; Janzen and Carter 2019). In the case of pastoralists, droughts can decrease the herd size to a critical level, leading to a poverty trap (Chantarat et al. 2017). The threat of shocks (that is, risk), the shocks themselves (that is, adverse realized outcomes), and the strategies used to cope with them play a crucial role in the long-term well-being of rural households in developing countries (Rosenzweig and Binswanger 1993; Morduch 1995; Zimmerman and Carter 2003; Dercon 2004; Barnett, Barrett, and Skees 2008; Barrett and Carter 2013).

Ceballos and Robles (2014) identify several reasons why agricultural indemnity insurance has failed to expand successfully in developing countries. First, given that farms in developing countries are significantly smaller than in countries like the United States and Canada, traditional crop insurance products would have higher administrative costs as a percentage of total premiums. A portion of these costs are related to marketing and servicing (loss adjustment) insurance policies. Another portion is related to the lack of farm-level data and cost-effective mechanisms for controlling moral hazard. These costs are even larger if rural infrastructure is inadequate (lowquality roads). Moreover, the lack of formal financial service networks and legal records may add to the cost of premium collection and compensation disbursements.

Second, indemnity insurance is prone to significant information asymmetry problems such as adverse selection (whereby only the most at-risk farmers purchase insurance) and moral hazard (whereby an insured farmer may not exert optimal effort to reduce risk or mitigate its impact). Both problems generally result in an increased cost that would make purely private markets nonviable even in developed countries. Third, developing countries have more limited fiscal resources to support and subsidize indemnity products than do developed countries; and since larger segments of the population are engaged in farming, the scarcity of fiscal resources is even more acute. More important, the opportunity cost of those limited fiscal resources may be significantly greater than in a developed country. Fourth, developing countries have far less access to global crop reinsurance markets than do developed countries. Reinsurance contracts typically involve high transaction costs related to due diligence. For a global reinsurer to be willing to enter a market, the enabling environment must foster confidence in contract enforcement and institutional regulations. An enabling environment is, in fact, a prerequisite for effective and efficient insurance markets, and these components are largely missing in developing countries. 
Index insurance is promoted as a low-cost alternative for conventional insurance products (Alderman and Haque 2007; Barnett, Barrett, and Skees 2008; Hazell et al. 2010; Mahul and Stutley 2010). With index insurance products, payments are based on an independent measure regarded as highly correlated with farm-level yield or revenue outcomes. Unlike traditional crop insurance that attempts to measure individual farm yield loss or revenue loss, index insurance makes use of variables exogenous to the individual policyholder-such as temperature or rainfall measurement-but have a strong correlation to farm-level losses. The index can also be an average in an outcome related to loss over a small area, such as average crop yield or livestock mortality rate. They can be estimated using statistical sampling (such as random crop cuttings) or average pasture damage based on satellite observations.

As an example of a typical weather index insurance product, consider the one presented by Ceballos, Kramer, and Robles (2018) to insure Indian wheat farmers against excessive unseasonal rains. They use the maximum accumulated rain (in millimeters) over any two consecutive days during February through April as the index that could trigger a payment. And that happens when the index takes a value equal to or higher than a number called the index strike. The higher the index value, the higher the compensation per acre to the farmer up to a maximum that reflects the cost of production per acre. The index value is computed using data from a local reference weather station. It is relevant to discuss the following aspects that are common to most agricultural index insurance products.

\section{The Index}

The selected index must be highly correlated with yield loss or revenue loss for farms across a geographic area. Ideally one would like to use data on historical yields and rainfall to establish a model (mathematical, statistical, or agronomical) to help select the best index. Unfortunately, in many rural contexts in developing countries, such data are not available and/or the data quality is very low. Consultation with farmers and local experts can help identify the best index selection. The index must satisfy other properties that would make clients trust the product.

First, the index must be observable and easily measured by an independent party. Typically the national meteorological agency is the best candidate to measure weather data as it has the expertise and reputation to do it as part of its regular activities. Based on daily weather records the independent party can periodically (daily) compute the index and make the information publicly available through, for example, a website or local media. Second, the index 
must be calculated objectively following well-defined protocols known to all parties involved, including farmers. Such protocols should include the datacollection process, the specific formula for index value calculation, and how to handle contingencies such as temporary weather station malfunctions.

Third, the index must not be subject to tampering and human manipulation. This implies setting supervision protocols and restricting access to weather stations. In a 2015 weather index program implemented in Uruguay, automatic weather stations were installed in police stations to ensure proper supervision. Having algorithms that can quickly detect abnormal changes in rainfall or index values can help detect tampering and/or malfunctioning. Finally, the index should be reportable in a timely manner. When insured farmers suffer a crop loss, the faster the insurance payment arrives the better. Working with automatic weather stations or satellite data can significantly reduce the time to report the index and determine payment amounts and that can quickly reach the affected farmers.

\section{The Payment Schedule}

Payment amounts are estimated ex-ante, based on the best available prediction on what could be the yield loss for every possible value of the index and considering partial and full crop loss. In general, the payment schedule is structured as a function that goes from index to payment, and in principle this function could take different shapes depending on how the estimated crop loss is related to the index. In practice, most index products take a linear payment function to compensate for ex-ante estimated partial crop loss up to a point beyond which full crop loss is assumed.

\section{Main Advantages of Index Insurance}

There are three main reasons why index-based insurance has been regarded as having great potential to reach smallholder farmers in developing countries.

1. Lower administrative costs. Given that payments are based only on publicly observed data, inspections of individual farms are not required, thus reducing drastically loss verification costs. The cost of sending an agent to assess yield loss at a remote small farm can be quite large relative to the insurance compensation, making premiums too high to be financially viable. With index insurance this cost is eliminated and replaced by the cost of generating, collecting, and reporting index data.

2. Asymmetric information problems are minimized. Two classical problems in the insurance literature are moral hazard and adverse selection. 
Deductibles, copayments, or other partial payments for loss are commonly used by traditional indemnity insurance providers to mitigate these problems, although the evidence for agricultural insurance in particular is that informational problems are high enough to prevent the existence of purely private all-risk crop insurance markets. However, index insurance is not subject to moral hazard as the likelihood of making payments does not depend on the client's behavior but only on the index value. Clients have no incentive to take extra risk as they will not be protected for the additional risk. Similarly, adverse selection problems are much lower with index insurance because the likelihood of insurance payments is not affected by the type (high or low risk) of farmer buying insurance but only by the probability that the index will trigger payments. High risk farmers might select themselves in buying more insurance compared to low risk farmers, but this will not be an "adverse" selection as it will not have an impact on the average insurance payments. Also, it is very unlikely that farmers will have better information than the insurer regarding the probability distribution of the index value. Because index insurance is not subject to asymmetric information problems, there is less need for deductibles and copayments and few restrictions need to be placed on the amount of coverage a farmer decides to purchase.

3. Quick payment disbursement. Index insurance compensations can be quickly determined based solely on index readings and the preestablished payment schedule. Therefore payments can be disbursed quickly to farmers not long after the end of the coverage period (in some cases even before). New technologies are helping to make the disbursement compensations even faster. With automatic weather stations that can report weather variables online, the index can be computed and reported at a very high frequency (daily) and compensations calculated immediately. Also, with more farmers accessing mobile banking, they will see payments in their accounts as soon as the insurer and corresponding bank authorize them.

\section{Index Insurance Challenges}

Although index insurance has some important advantages that make it a promising product among smallholder farmers in developing countries, it presents some disadvantages that prevent an agricultural microinsurance revolution based on index-based products. 


\section{BASIS RISK}

"Basis risk" refers to the potential mismatch between index-triggered payouts and actual losses. It occurs when an insured farmer has a loss and does not receive an insurance payment sufficient to cover the loss that resulted due to the insured risk. This is known as "downside basis risk." The opposite situation, referred to as "upside basis risk," takes place when a farmer has a loss (or no loss at all) and receives a compensation that exceeds the loss amount. Clarke (2016) formally defined basis risk as the unconditional probability of both experiencing a critical loss and not receiving an insurance payout (downside basis risk) or as the unconditional probability of both not experiencing a critical loss and receiving an insurance payout (upside basis risk). The worst situation would be one in which an insured farmer has total or close-to-total crop loss and the observed index does not trigger any payment.

According to Ceballos (2016), a broad characterization of the different components of basis risk can be thought of as (1) spatial basis risk and (2) design risk. "Spatial basis risk" is related to the geographic variation between the index being measured at the farmer's plot and the index being measured somewhere else-for example, at a distant weather station. Since the relevant rainfall that explains crop yields is the rainfall at the farmer's plot, the larger the distance between the reference weather station and the farm of the insured farmer the lower the expected correlation between the index (computed with data from the reference weather station) and crop yields. "Design basis risk" is related to the design of the insurance product, including the choice of the weather variable(s) and the specific index as well as the functional form of the payment schedule. Even if there were a weather station at every farm (no spatial basis risk), the correlation between crop yield loss and the index can be far from perfect. Also, how specifically one links the index to payments (for example, linearly) could be another source of basis risk. The more data and knowledge from experts, the higher the chances to select a better index and payment schedule to maximize the correlation with farmer losses.

In practice, there is a third source of basis risk that is related to idiosyncratic farmer characteristics. In the design of an index product one collects the best data and expert knowledge available to design a product targeting the typical or average farmer in a region. However, farmers could be heterogeneous in several dimensions, including farming practices and plot characteristics (such as soil quality) that make them depart from the "average" regional farmer. Therefore the index product might not perfectly fit the risk profile of any farmer other than the "average" one. 
An index product with too much basis risk is an insurance product that offers poor insurance coverage as payments do not come when most needed (high losses) and might come when not needed (no loss). It is expected that above a certain level of basis risk a farmer would not demand the index product (see Clarke 2016 and Hill, Robles, and Ceballos 2016 for a formal discussion). Also, basis risk might introduce behavioral aspects that would make index-based products even less appealing. For example, Carter, Elabed, and Serfilippi (2015) show that in the presence of basis risk, farmers might become excessively sensitive to insured basis risk in a way that is not consistent with standard expected utility theory.

\section{LACK OF INFRASTRUCTURE AND INFORMATION}

To design index products, historical data are needed to correctly estimate probabilities of triggering payments and to price the product. In developing countries, especially in rural areas, this could be a serious limitation as such historical data are nonexistent or of poor quality. Data limitations have been emphasized by Miranda and Farrin (2012) and others as a serious constraint to the expansion of index insurance programs beyond small-scale pilots, and they suggest that governments and donors should take responsibility for collecting and maintaining index data, given their public-good nature. Similarly, a dense network of weather stations is needed as one would like to limit spatial basis risk. Again, in developing countries these networks are often not very dense. One way to overcome these limitations is by using satellite information to proxy for weather information and/or other variables that can inform about crop yields (greenness index, area leaf index, and so on).

\section{COMPLEXITY}

Index products are not necessarily easy to understand for potential clients, especially as the level of education among smallholder farmers in developing countries is unfortunately still low. As farmers might not easily understand an insurance product that pays based on readings from a distant weather station, or even worse based on satellite information, they might be reluctant to purchase it. Several studies reviewed in the next section show how lack of product understanding explains low insurance demand. While private insurers might invest in marketing their products, Hazell and Hess (2016) suggest that their educational efforts will be far from socially optimum levels and that government and donor interventions will be required. Also, designing and pricing index products is not straightforward and requires professionals with relevant expertise. In many instances these professionals might not be available locally 
or among the staff of local microfinance institutions that would be natural candidates to design and offer index products to smallholder farmers. This might limit the supply.

\section{The Current State of Agricultural Index Insurance in Developing Countries}

Hazell and Hess (2016) estimate that the total number of insured smallholders in 2014 in the developing world is 198 million, with approximately 650,000 in Africa, 3.3 million in Latin America and the Caribbean, and about 194 million in Asia, including 160 million in China and 33 million in India. ${ }^{2}$ Other estimates are provided by the regional landscape studies conducted by the Micro Insurance Centre, as part of the Microinsurance Network's World Map of Microinsurance (Microinsurance Network n.d.). A total of 1.1 million Africans were identified as being covered by agricultural microinsurance as of the end of 2014 (Micro Insurance Center 2016). Since 2014, index-based agricultural microinsurance has become more popular in Latin America and the Caribbean; the number of people covered by agricultural insurance has increased by 129 percent, from 35,000 in 2014 to 80,000 in 2017 (A2F Consulting 2018). In Asia and Oceania the number of people covered by agricultural microinsurance in 2012 is estimated at 23.8 million, and agricultural products were registering the highest growth of all microinsurance product types. These numbers do not include social agricultural microinsurance schemes, which are mainly delivered as products tied to crop loans in these countries. China's PICC agricultural insurance scheme is the largest scheme and covers more than 100 million individuals. India's National Agricultural Insurance Scheme and Pakistan's Crop Loan Insurance are also large programs with an outreach of 16.3 million and 10.5 million respectively.

The most comprehensive study assessing the extent of agricultural insurance around the world was conducted by Mahul and Stutley (2010) based on a survey of 65 countries and showing the situation through 2007. Hazell and Hess (2016) summarize very well the most salient facts of this study, among them:

2 See Hazell and Hess (2016), Appendix 1, for a detailed list of agricultural insurance programs in the developing world. 
- Lower-middle-income and low-income countries accounted for only 7.5 percent of the total agricultural insurance premiums (including premium subsidies) of US\$15.1 billion.

- Market penetration remains small, even in rich countries. The total insurance premium collected (including subsidies) amounted to 0.9 percent of agricultural gross domestic product, ranging from virtually zero in lowincome countries to 2.3 percent in high-income countries ( 5 percent in North America).

- 82 percent of countries offered both crop and livestock insurance, but crop insurance accounted for 90 percent of the premium.

- Multiple-peril crop insurance was available in 65 percent of the countries but was most popular in the middle-income countries. Named peril insurance was even more widely available (in 69 percent of countries) and was even available in half of the low-income countries.

- Index-based crop insurance is available, mainly at a pilot stage and with very low aggregate premium volume, in one in three surveyed countries. Area-yield insurance was available in 15 percent of the countries, and weather-index insurance in 22 percent of countries. Index-based insurance had also penetrated the low-income countries; 17 percent had area-yield insurance and 33 percent had weather-index insurance.

Although index-based insurance has been regarded as having great potential to reach smallholder farmers in developing countries, attracting a lot of attention from donors, international organizations, governments, researchers, and microfinance institutions, most programs have repeatedly experienced low take-up, due to among other reasons basis risk (low-quality products), lack of trust in the insurance company, lack of understanding of the product, liquidity constraints, or crowding out of insurance by implicit public guarantees. Currently India is the country with the largest partially subsidized agricultural index insurance program with more than nine million farmers purchasing index products, although this can be explained to a large extent by the fact that agricultural insurance is mandatory for those who want access to agricultural credit.

Some of the most successful cited index-based insurance programs in the developing world are the following (see Greatrex et al. 2015 for a full description of these programs): 
- The Indian National Agricultural Insurance Scheme (NAIS) started in 1999 and over time has been complemented by the modified NAIS (mNAIS) and the Weather-Based Crop Insurance Scheme (WBCIS). These programs insure cereals, millets, pulses, oilseeds, and horticultural products. In 2013 the programs provided coverage to 16.79 million farmers under NAIS, 3 million under mNAIS, and 13.62 million under WBCIS. Considering that the number of farmers in 2011 is estimated at 118.7 million, insurance penetration was at most 28 percent at the country level. ${ }^{3}$ The programs are state-subsidized.

- The Agriculture and Climate Risk Enterprise (ACRE, formerly Kilimo Salama) started in 2009 and now operates in Kenya, Rwanda, and Tanzania. In 2013 it provided coverage to more than 187,466 farmers, 60 percent in Kenya and 40 percent in Rwanda, for the following crops: maize, beans, wheat, sorghum, coffee, and potatoes. The program has strong links to aggregators and mobile technology and offers a wide range of products, mostly linked to credit or inputs.

- R4 Rural Resilience Initiative (formerly HARITA) started in 2009 in Ethiopia and now operates in Senegal as well. In 2014 it provided coverage to 24,133 farmers in 82 villages in Ethiopia and 1,989 in Senegal to insure teff, beans, maize, wheat, barley, sorghum, and millet. This is a farmer-led, integrated risk management project in which farmers can pay premiums with labor employed in risk-reduction projects. Satellite rainfall indexes are used in the design of products.

- Index-Based Livestock Insurance Project in Mongolia was created in 2006. In 2014 it provided insurance for livestock (camels, cattle, sheep, goats, and horses) of approximately 15,000 herders. This is a public-private partnership with innovative risk layering.

- Index-based livestock insurance started in 2010 in Kenya and provides protection against drought to pastoralists with camels, cattle, sheep, and goats (Chantarat et al. 2013). Approximately 3,000 contracts have been sold up to 2016. This is an innovative cattle mortality index-based insurance based on satellite data and a normalized difference vegetation index (NDVI).

3 See India, Ministry of Agriculture (2018). 


\section{Index Insurance Take-Up: Empirical Evidence}

Most agricultural index insurance pilot programs in developing countries show that the overall demand for index products is still very low even in the presence of large premium subsidies. Among multiple studies, in India, Gine, Townsend, and Vickery (2008) report a lower than 5 percent take-up rate in Andhra Pradesh, and Cole et al. (2013) report that in 2006 one contract was estimated to be sold for every 13.2 households in Indian villages where rainfall insurance contracts were available and households that buy insurance generally purchase just one or two policies, hedging only a modest fraction of monsoon agricultural income. Hill, Robles, and Ceballos (2016) report overall take-up rates of 6.8 percent and 4.0 percent during 2011 and 2012 , respectively, in Madhya Pradesh. A more encouraging study is Karlan et al. (2011), reporting a 40 percent to 50 percent take-up in Ghana at fair price plus a 50 percent loading, although there is an income effect as farmers were offered grants to access insurance products. In sum, uptake to this date has been generally disappointing, and the empirical and academic literature on demand for index insurance has mostly focused on household and contract characteristics that vary within a given project (Jensen and Barrett 2017). This approach is useful for conducting econometric analysis to study marginal impacts in the demand for insurance.

Basis risk is a usual suspect to explain low demand for index products. The higher a product's basis risk, the less hedging it provides to a farmer (Miranda and Farrin 2012; Binswanger-Mkhize 2012; Clarke 2016). Studies that quantify basis risk find that it can be considerable. Jensen, Barrett, and Mude (2016) find that in the Index-Based Livestock Insurance (IBLI) program in northern Kenya, policyholders are left with an average of 69 percent of their original risk; in other words 69 percent of all potential losses are not compensated by the insurance product. This is surprisingly high as the IBLI product is regarded as close to a best-case scenario since the index was selected based on a regression model using a long panel of household data to expressly minimize basis risk.

Although IBLI reduces exposure to covariate risk by an average of 63 percent, the presence of idiosyncratic risk is high, accounting for a large overall basis risk. Clarke et al. (2012) find in the Weather Based Crop Insurance Scheme (WBCIS) in India that the relationship between claim payments and yields appears to be rather weak, with low average claim payments in the event of extreme yield losses (in the event of a zero yield, the average WBCIS claim payment is only 12 percent of the sum insured). They estimate that conditional on total crop loss (average crop yield of zero), there is a 
one-in-three chance of receiving no claim payment from the WBCIS. Other studies estimate by how much exogenous variations in basis risk (proxied by distance to weather stations) reduces demand for index products. Hill, Robles, and Ceballos (2016) find that doubling the distance to a reference weather station decreases demand by 18 percent. Mobarak and Rosenzweig (2012) estimate that for every kilometer increase in the (perceived) distance of the weather station for a farmer without any informal risk protection, there is a drop-off in demand for formal index insurance of 6.4 percent. Karlan et al. (2014) and Jensen, Barrett, and Mude (2016) also study the impact of basis risk on demand, although they don't have access to exogenous variations to basis risk.

Lack of product understanding is also regarded as an important driver for low take-up of index insurance. Index-based products might not be easy to understand, which is made even more problematic by the low levels of formal education among small farmers in developing countries. For example, Hill, Robles, and Ceballos (2016) report that on average farmers with 3.5 acres of land have less than 4.5 years of formal education in a selected sample of relatively better-off small famers in Madhya Pradesh, India. In Karlan et al. (2014) only 15 percent of farmers in the selected sample are literate; these are farmers that on average have less than 8 acres of land. Similarly, Cole et al. (2013) show that 67 percent of household heads in Andhra Pradesh and 42 percent in Gujarat have at most primary school education.

Also, many smallholder farmers have no experience with formal measurements of weather variables and, for example, cannot relate to rainfall measured in millimeters per day. Satellite data, normalized difference vegetation index, and leaf area index are all unknown concepts for most of them. And experience with any type of formal insurance contract or product is also not common. All these elements make the understanding of index products difficult. Hence promoting the demand for index-based products requires educating farmers on the general concepts of insurance and the specifics of index insurance products. Experimental studies have found that improved understanding of the product is an important demand driver. Hill, Robles, and Ceballos (2016) find that the impact that increased investments in training have on demand for weather-index products is significant in the short term. Households that receive more intense training are 5 percentage points more likely to purchase the insurance product in the season immediately following the training. Gaurav, Cole, and Tobacman (2011) find that a two-day educational program, involving games that simulate rainfall insurance, did increase rainfall insurance demand by 5 percentage points. 
Another challenge to demand is trust. Index insurance pilots often are implemented in regions where insurance companies have little or no presence and where farmers have no previous experience with insurance products in general. In these regions there is little legal recourse in reclaiming insurance payments. For index insurance, the expected payout is difficult to know because the relationship between weather and loss is imperfect. And when the insurance provider is better informed on risk, farmers must rely on the insurance company in setting a fair price. Relations of trust with the insurance provider and its agents are thus very important for uptake. Lack of trust resulting in low willingness to pay for index insurance has been confirmed experimentally. Cole et al. (2013) show that endorsement of the insurance product from a trusted third party increased uptake by 40 percent compared with farmers who heard of no endorsement. In the context of an insurance for sows and a large randomized natural field experiment conducted in southwestern China, Cai et al. (2009) provide several pieces of evidence suggesting that trust, or lack thereof, for government-sponsored insurance products is a significant barrier for farmers' willingness to participate in the insurance program.

Cai et al. (2015) find that in China trust is established by experiencing payouts to oneself or by witnessing payouts to members of your social network. Payouts were the main instrument in building trust, suggesting that trust can be increased by initial subsidies to boost demand and increases the likelihood of observing actual payouts, or by increasing the frequency of payouts by insuring smaller high-frequency losses in addition to larger low-frequency losses (Carter 2009). Dercon, Gunning, and Zeitlin (2016) have developed a theoretical model of insurance demand under limited trust and using field and laboratory-experimental data from a randomized controlled trial introducing a composite health insurance product to tea farmers in Kenya. They find evidence that limited trust is an important barrier to the adoption of insurance, particularly among poor and risk-averse households.

Hellmuth et al. (2009) document that (1) in an Indian contract farming case study involving PepsiCo, farmers trust the program because of its timely settlement of claims; (2) Oxfam's long-standing presence in Ethiopia, combined with high levels of respect and trust for its local partner NGO, the Relief Society of Tigray (REST), made farmers willing to explore weatherindex insurance; and (3) feedback from Thai farmers suggested that the primary motivation for purchasing insurance was trust in the Bank for Agriculture and Agricultural Cooperatives (BAAC), an institution that has long-term relationships with the farmers. They conclude that the lesson is clear: identifying partner organizations that farmers already trust is critical 
to successfully scale up index insurance programs. Government regulation and providing legal recourse to farmers is also important in building trust on insurance schemes because premiums are generally paid at the onset of insurance contracts, leaving farmers with the risk associated with contractual nonperformance. Karlan et al. (2014) conclude that trust is a key issue that can be tackled through product design (increasing states of the world with payouts), proper linkage with trusted institutions, and proper regulation.

Demand for index insurance is price sensitive. Jensen, Barrett, and Mude (2017) report that published estimates of price elasticities range from -0.35 to -1.16 , and often demand remains very low even when premiums are heavily subsidized. Cole et al. (2013) found insurance demand in the Indian states of Andhra Pradesh and Gujarat to be highly price elastic, with a 10 percent reduction in the price of insurance associated with a 10 percent to 12 percent increase in insurance take-up. Karlan et al. (2014) find that 40 percent to 50 percent of Ghanaian farmers purchased insurance at actuarially fair prices, but take-up rates dropped to 10 to 20 percent when charged double the actuarially fair price. Mobarak and Rosenzweig (2012) find the price elasticity of insurance demand to be -0.44 , and Hill, Robles, and Ceballos (2016) estimate the price elasticity as -0.58 and show that price elasticity is sensitive to different levels of basis risk. They find that households located less than 5 kilometers from a weather station have a sensitivity to price almost 10 times higher than that of those located more than 12 kilometers from a weather station.

Standard insurance models predict that in the absence of basis risk, demand for insurance is increasing with the degree of risk aversion. However, Clarke (2016) provides a theoretical framework predicting that in the presence of basis risk and premiums above the actuarially fair price there is a hump-shaped relationship between demand and risk aversion: insurance demand is initially increasing with risk aversion before decreasing such that, for very risk-averse farmers, purchasing insurance makes them worse off. Hill, Robles, and Ceballos (2016) provide indicative evidence of the predicted hump-shaped demand for index insurance.

Liquidity constraints have been shown to be important to demand rates across a variety of products and populations, which suggests limitations in the use of commercial index insurance as a tool for helping the poorest subpopulations (Jensen, Barrett, and Mude 2016). Note that farmers would have to buy agricultural insurance at the start of the growing season, when there are many competing uses for limited funds increasing the opportunity cost of insurance. Giné, Townsend, and Vickery (2008) provide empirical evidence 
that credit constraints reduce the probability of take-up by 30 percent. Cole et al. (2013) find suggestive experimental and nonexperimental evidence that liquidity constraints reduce demand. After randomly assigning certain households with high cash rewards (enough to buy one policy), they observe that take-up increases by 140 percent with a magnified effect among poor households, which are likely to have less access to credit markets.

Jensen, Mude, and Barrett (2018) find suggestive evidence that reducing liquidity constraints is associated with an increase in the demand for indexbased livestock insurance (IBLI) in northern Kenya. Two studies remove credit constraints by directly postponing premium payments until harvest time. Liu et al. (2016) finds that for a government-managed livestock mortality insurance in China, delaying premium payment increases take-up from 5 percent to 16 percent. Casaburi and Willis (2018) show that in the context of a randomized controlled trial in Kenya, take-up goes from 5 percent to 72 percent among sugarcane producers. However, insurance companies will not be willing to postpone premiums until harvest time unless new mechanisms to enforce premium payments are available. In Casaburi and Willis (2018), default on premiums is less of a concern since the product is interlinked with a contract farming scheme.

Most of the empirical work studying the demand for index insurance has the standard expected utility theory as the theoretical framework. However, recent work based on behavioral economics provides additional explanations for low index insurance take-up. Carter, Elabed, and Serfilippi (2015) find that substantial numbers of farmers depart from expected utility behavior in ways that predict excess sensitivity to uncovered basis risk in index-based insurance contracts. Experiments by Elabed and Carter (2015) find that farmers perceive index-insured risk as a compound lottery with uncertainty around the insured risk and uncertainty around how well the index will reflect their losses (basis risk). They find that 60 percent of their sample from southern Mali are compound risk averse and that in the presence of moderate basis risk, the levels of compound risk aversion observed in their sample could cut demand for index insurance in half, amplifying the already detrimental impact of basis risk on demand.

In a dynamic setting, an interesting piece of evidence shown by Cole, Stein, and Tobacman (2014) is that demand is highly sensitive to payouts being made in a household's village in the most recent year, with the effect being stronger when more individuals in a village receive payouts, and the effect remains positive over multiple seasons, but the estimated size decreases over time. As pointed out by the authors, these results stand in contrast to standard 
rational models, in which the realization of recent insurance outcomes should not affect forward-looking insurance decisions.

\section{Challenges and Recommendations to Scale Up Agricultural Insurance in Developing Countries}

The main challenge of agricultural insurance in developing countries is how to create sustainable agricultural microinsurance markets. To meet this challenge, the following three elements are needed: (1) designing high-quality products that are commercially viable with minimum possible government support, (2) existence of a large and sustained demand, and (3) presence of a competitive supply mainly from the private sector. Given limited resources in developing countries and many other sectors requiring attention, promoting strong private-sector participation in agricultural microinsurance markets complemented with well-targeted government support is the most realistic option.

The evidence with traditional all-risk indemnity insurance programs in developed countries is that they require massive government support because of high costs due to information asymmetries (moral hazard and adverse selection), let alone the political economy behind disguised transfers from tax payers to farmers as premium subsidies. The small-scale nature of farming in developing countries would add costs to such traditional insurance schemes, making them nonviable unless new technologies or approaches make them feasible at affordable rates to either small-scale producers or governments willing to provide support within their limited budgets. In a broader context agricultural microinsurance markets should provide incentives to adopt best agricultural practices rather than substitute for them, complement other efficient risk management strategies such as risk-reduction investments including newly available seed varieties that have tolerance to abiotic shocks, such as flood, drought, and extreme temperatures, and when possible become an ex-ante system for government disaster risk management.

\section{High-Quality Insurance Products Commercially Viable}

A high-quality agricultural insurance product is one that compensates farmers when and only when they suffer a crop or income loss and the amount of the compensation is in direct proportion to the size of the loss. It is known that traditional indemnity insurance products are in this sense high-quality products but unfortunately, because of information asymmetries and monitoring and loss assessment costs, they are not commercially viable. Index-based products, however, have low monitoring and loss assessment costs and minimize 
if not eliminate information asymmetries, but they introduce basis risk, the imperfect relationship between the indemnity payments and the actual insured losses. When basis risk is too high, the insurance product is more like a lottery ticket. Most efforts are being placed in trying to reduce basis risk for index-based products.

Recent innovations in index insurance design are worth noting (Jensen and Barrett 2017). The ACRE product in Kenya provides a menu of coverage options, each developed to cover a specific agricultural phase, allowing clients greater flexibility in the risk that they choose to insure. The index-based livestock insurance (IBLI) product in Kenya used historical household-level data and econometric methods to statistically minimize expected basis risk. Hill and Robles (2010) have proposed an approach that is based on a variety of weather contracts in a region and then allow individual farmers the flexibility to form their own portfolios of weather contracts that best match their own crop mix and locational characteristics.

The following actions will help in designing better index products (see Hazell and Hess 2016 and Carter et al. 2017):

- Increase the number and dispersion of weather stations to better capture the spatial diversity of farming conditions in a region. Technological advances are rapidly reducing the cost of adding automatic weather stations, and in some countries private firms offer weather station services for a fee (for example, India). Although additional weather stations could add to the cost of developing and marketing index contracts, and as new weather stations come without site-specific historical records, the calculation of "synthetic" datasets based on the triangulation of existing historical weather data will be required.

- Invest in agrometeorological research and crop-weather modeling to identify weather indexes that minimize basis risk for as many households as possible in a region given the available weather data.

- Insure groups of farmers who can pool basis risk among themselves through local institutions. This idea is based on the theoretical work of Dercon et al. (2014) that has been explored in a series of insurance games by McIntosh, Povel, and Sadoulet (2019).

- Limit the insurance to the kinds of low-frequency, high-impact weather risks that affect most people in a region at the same time. In this case individual losses would be more highly correlated with the insured weather station event (Giné, Townsend, and Vickery 2007). 
- In the absence of weather stations and any local weather data at all, areabased yield insurance might be a viable alternative. Mongolia has pioneered a livestock insurance program in which the index is a county-level livestock mortality rate measured through an annual livestock census (Hellmuth et al. 2009).

- Complement the primary index-based contract with a secondary contract that can be index-based over a broader area or damage assessment-based (Carter et al. 2014), minimizing as much as possible downside basis risk by adding an audit rule (see Flatnes and Carter 2015) that, for example, is triggered when more than a certain fraction of farmers after not being compensated request a sample of crop-cutting exercises.

There has been a lot of recent innovation in developing indexes that can be assessed remotely with satellites at a high resolution (for example, 5 hectares), such as cloud cover, vegetative cover, or soil moisture content for a chosen region during critical agricultural periods.

A more recent and innovative approach-picture-based insurance (PBI) aiming at developing high-quality insurance products-has been proposed by Ceballos, Kramer, and Robles (2019). It is based on taking regular georeferenced pictures using smartphones as a mechanism to deliver plot-level assessments of damage at low cost. This approach takes a different direction in the sense that it moves away from a standard index-based product and goes back to the idea of traditional indemnity insurance but using new technologies to reduce loss assessment verification costs. The aim of PBI is to combine key advantages of both index-based insurance (timely compensations without expensive loss assessments) and indemnity insurance (minimum basis risk and an easy to understand product).

The product takes advantage of recent advances in image processing for near-surface remote sensing (see Richardson et al. 2018), aims to apply machine learning in developing algorithms that can capture accurately losses from a time-series of images, and expects that direct participation of farmers in the insurance process will increase understanding of and trust in the product. While PBI is being tested at a small scale with wheat farmers in India, interestingly Kramer et al. (2017) find indicative evidence that farmers are willing to pay more for PBI than for a comparable weather index-based product. The main challenge of this approach would be to overcome possible moral hazard and adverse selection issues and to enforce that insured farmers comply with picture taking according to certain protocol. One option to be explored 
is to link PBI with agro-advisory services based on the same time-series of images. In any case, PBI is a work in progress.

\section{Large and Sustained Demand}

So far, the only forms of index insurance to be adopted at scale have been areayield insurance in both China and India, which are heavily subsidized, and in the Indian case, are compulsory for farmers who take agricultural loans from state banks. Everywhere else in developing countries the demand is very low, limiting the interest of private providers to participate in these markets. To have a larger demand, the first step is to have a high-quality product and more generally a value proposition to farmers. As explained earlier, a high-quality index product is one with no or small basis risk. But besides having a high-quality product, there are other options that can help in inducing a higher demand.

A major challenge to demand is client education and trust. Here there is a role for government intervention by providing insurance literacy programs among potential clients. Also, the government has a critical role in providing a sound regulatory environment to provide standards for consumer protection and improving trust. This should include standard insurance regulations, such as minimum capital-to-liability holdings requirements for insurers and reinsurers, clear index certification processes, a process for speedy and accessible disputed settlement resolutions and regulations, allowing for unconventional insurance agents such as NGOs or microfinance institutions (Jensen and Barrett 2017), which are more familiar to small farmers.

Developing quality standards and metrics for measuring and disseminating information on product quality is highly recommended (Carter et al. 2017). Assuming a latent untapped demand for high-quality insurance exists, if consumers could distinguish between two equally priced products of differing quality, market forces could be relied on to reward investments in quality (Jensen and Barrett 2017). Providing smart subsidies is another possibility (Hazell and Hess 2016). The evidence shows that agricultural microinsurance is unlikely to ever scale up quickly without increased levels of public support by governments and donors. Provision of subsidies is more obvious when insuring disaster relief agencies, given difficulties in recovering costs from poor beneficiaries. More generally, if subsidies are not used carefully, they might encourage farmers to take on too much risk and environmentally damaging practices, increasing their dependence on future subsidized assistance. For using subsidies in smart ways that avoid creating disincentive problems, or 
becoming a financial burden on the state, the following principles should be applied:

- Subsidies will be less distorting if made directly to the insurer to offset administration and development costs rather than subsidizing the premium rates paid by farmers.

- If premium rates are to be subsidized, it is better to do this on an advalorem - that is, per farmer basis—rather than on a risk-premium proportional basis, to benefit smaller and poorer buyers who buy smaller amounts of insurance.

- The final subsidized net premium for the farmer should not be lower than the pure risk, so that farmers will not have an incentive to gamble the system or plant the wrong crops in the wrong areas.

- There should be an explicit exit strategy or strategy for long-term financing.

Expanding index insurance beyond farmers may be desirable, as it has the potential to insure many other types of rural people who are engaged in nonagricultural activities that are dependent directly or indirectly on local agriculture-for example, agricultural traders and processors, landless workers, and village shopkeepers.

Recently Casaburi and Willis (2018) show that postponing premium payments until harvest time can go a large way in boosting insurance take-up. As they rightly point out, the gains from insurance arise from the transfer of income across states of nature, and by requiring premiums to be paid upfront, insurance products will also transfer income across time with no value-added. Credit and savings are financial instruments much better suited to transfer income across time. The reason why premiums are required to be paid upfront by insurance companies is to avoid defaults on premium payments. Therefore innovations that would allow postponement of premium payments while at the same time minimizing defaults are required.

Carter et al. (2017) argue in favor of offering index-based insurance to a mesolevel institution-such as a bank that might offer agricultural loans, an administrative entity, or a producer organization—as a potentially attractive option. In the case of banks, they worry about large correlated shocks that might affect their entire portfolio of agricultural loans in a given region. This implies that basis risk is less of a problem for such a mesolevel institution. Farrin and Miranda (2015) show in the context of a heterogeneous agent 
model that when banks lay first claim on indemnities there is a reduction in credit default, which can decrease interest rates and expand credit access among farmers. De Janvry, Dequiedt, and Sadoulet (2014) also support the idea of insuring farmer groups, especially when farmers are members of groups with common interests.

\section{Competitive Supply Mainly from the Private Sector}

Index insurance needs insurance companies willing and capable to sell the product in rural communities. In most cases available insurance companies and brokers have a well-established presence in urban centers but are typically unfamiliar with the rural customer base. Before index insurance can be offered, sales agents need to be trained in the new product, and since farmers may not trust insurance agents from outside their region, an entirely new sales force may need to be recruited and trained (Jensen, Barrett, and Mude 2017). If the insurance is linked to other products (for example, fertilizer, seed, or credit), additional legal arrangements also need to be developed.

Availability of reinsurers for specialized agricultural insurance products in developing countries is limited, and typically they offer very high rates that end up being reflected in high premiums. Giné, Townsend, and Vickery (2007) emphasize the importance of having reinsurance mechanisms to diversify regionally covariate weather shocks, and Carter (2013) points out that in the absence of adequate high-quality data, uncertainty-averse reinsurers place a large premium penalty on uncertainty. Regional or domestic public reinsurance could be put in place to incentivize a more competitive behavior among reinsurers. For example, the African Risk Capacity, a specialized agency of the African Union, provides alternative risk pooling and transfer mechanisms that may directly or indirectly improve the reinsurance market for index insurance.

To address the problem of collecting premiums and making payouts in a timely and cost-effective manner, some insurers are taking advantage of mobile phone and mobile banking technologies. A good example is the ACRE program in East Africa, which enables farmers to pay their insurance premiums and receive payouts via the M-PESA mobile banking system (Hazell and Hess 2016). On the supply side of microinsurance products there is also a first-mover problem: the high initial investment costs in research and development of index insurance products might not be recouped given the ease with which competitors can replicate such products if they prove profitable to sell. Therefore, there may be an important public role in funding the development of index insurance products. 


\section{References}

A2F Consulting. 2018. The Landscape of Microinsurance in Latin America and the Caribbean 2017.

Final Report: The World Map of Microinsurance. Luxembourg: Microinsurance Network; Munich: Munich Re Foundation.

Alderman, H., and T. Haque. 2007. Insurance against Covariate Shocks: The Role of IndexBased Insurance in Social Protection in Low-Income Countries of Africa. No. 95. Washington, DC: World Bank Publications.

Arias, D., and K. Covarrubias. 2006. "Agricultural Insurance in Mesoamerica: An Opportunity to Deepen Rural Financial Markets." Inter-American Development Bank-Economic and Sector Study Series RE2-06-006. Washington, DC: Inter-American Development Bank.

Bakst, D., J. Sewell, and B. Wright. 2016. “Addressing Risk in Agriculture.” Heritage Foundation Special Report 189. Washington, DC: Heritage Foundation.

Barnett, B. J., C. B. Barrett, and J.R. Skees. 2008. "Poverty Traps and Index-Based Risk Transfer Products." World Development 36 (10): 1766-1785.

Barrett, C. B., and M. R. Carter. 2013. "The Economics of Poverty Traps and Persistent Poverty: Empirical and Policy Implications." Journal of Development Studies 49 (7): 976-990.

Binswanger-Mkhize, H. P. 2012. "Is There Too Much Hype about Index-Based Agricultural Insurance?” Journal of Development Studies 48 (2): 187-200.

Cai, H., Y. Chen, H. Fang, and L.-A. Zhou. 2009. "Microinsurance, Trust and Economic Development: Evidence from a Randomized Natural Field Experiment." PIER Working Paper 09-034. Penn Institute for Economic Research, Philadelphia.

- 2015. "The Effect of Microinsurance on Economic Activities: Evidence from a Randomized Field Experiment." Review of Economics and Statistics 97 (2): 287-300.

Cai, J. 2016. "The Impact of Insurance Provision on Household Production and Financial Decisions." American Economic Journal: Economic Policy 8 (2): 44-88.

Cai, J., A. de Janvry, and E. Sadoulet. 2015. “Social Networks and the Decision to Insure." American Economic Journal: Applied Economics 7 (2): 81-108.

- 2016. Subsidy Policies and Insurance Demand. NBER Working Paper 22702. Cambridge, MA: National Bureau of Economic Research.

Carter, M. R. 1997. "Environment, Technology, and the Social Articulation of Risk in West African Agriculture." Economic Development and Cultural Change 45 (3): 557-590.

_ 2009. "Intelligent Design of Index Insurance Contracts for Smallholder Farmers and Pastoralists." In Innovations in Insuring the Poor, edited by R. Vargas-Hill and M. Torrero. Washington, DC: International Food Policy Research Institute (IFPRI). 
_.2013. "Sharing the Risk and the Uncertainty: Public-Private Reinsurance Partnerships for Viable Agricultural Insurance Markets." I4 Index Insurance Innovation Initiative Brief 2013-1. Feed the Future and UC Davis.

Carter, M. R., A. de Janvry, E. Sadoulet, and A. Sarris. 2014. “Index-Based Weather Insurance for Developing Countries: A Review of Evidence and a Set of Propositions for Up-Scaling." Foundation pour les études et recherches sur le développement international Working Paper 111. FERDI, France.

2017. “Index Insurance for Developing Country Agriculture: A Reassessment." Annual Review of Resource Economics 9 (1): 421-438.

Carter, M. R., G. Elabed, and E. Serfilippi. 2015. "Behavioral Economic Insights on Index Insurance Design." Agricultural Finance Review 75 (1): 8-18.

Casaburi, L., and J. Willis. 2018. “Time versus State in Insurance: Experimental Evidence from Contract Farming in Kenya." American Economic Review 108 (12): 3778-3813.

Ceballos, F. 2016. Estimating Spatial Basis Risk in Rainfall Index Insurance: Methodology and Application to Excess Rainfall Insurance in Uruguay. IFPRI Discussion Paper 1595. Washington, DC: IFPRI.

Ceballos, F., B. Kramer, and M. Robles. 2019. “The Feasibility of Picture-Based Insurance (PBI): Smartphone Pictures for Affordable Crop Insurance." Development Engineering 4: 100042.

Ceballos, F., and M. Robles. 2014. Weather Risks and Insurance Opportunities for the Rural Poor. 2020 Conference Brief 10. May 17-19, Addis Ababa, Ethiopia. Washington, DC: IFPRI.

Chantarat, S., A. G. Mude, C. B. Barrett, and M. R Carter. 2013. “Designing Index-Based Livestock Insurance for Managing Asset Risk in Northern Kenya." Journal of Risk and Insurance 80: 205-237.

Chantarat, S., A. G. Mude, C. B. Barrett, and C. G. Turvey. 2017. "Welfare Impacts of Index Insurance in the Presence of a Poverty Trap." World Development 94 (June): 119-138.

Clarke, D. J. 2016. “A Theory of Rational Demand for Index Insurance.” American Economic Journal: Microeconomics 8 (1): 283-306.

Clarke, D. J., O. Mahul, K. N. Rao, and N. Verma. 2012. Weather Based Crop Insurance in India. Policy Research Working Paper W PS 5985. Washington, DC: World Bank.

Cole, S., X. Giné, J. Tobacman, P. Topalova, R. Townsend, and J. Vickery. 2013. “Barriers to Household Risk Management: Evidence from India." American Economic Journal: Applied Economics 5 (1): 104-135.

Cole, S., X. Giné, and J. Vickery. 2017. "How Does Risk Management Influence Production Decisions? Evidence from a Field Experiment." Review of Financial Studies 30 (6): 1935-1970. 
Cole, S., D. Stein, and J. Tobacman. 2014. "Dynamics of Demand for Index Insurance: Evidence from a Long-Run Field Experiment." American Economic Review 104 (5): 284-290.

de Janvry, A., V. Dequiedt, and E. Sadoulet. 2014. “The Demand for Insurance against Common Shocks." Journal of Development Economics 106: 227-238.

Dercon, S. 2004. "Growth and Shocks: Evidence from Rural Ethiopia." Journal of Development Economics 74 (2): 309-329

Dercon, S., J. W. Gunning, and A. Zeitlin. 2016. “The Demand for Insurance under Limited Trust: Evidence from a Field Experiment in Kenya." Working paper presented at the Poverty and Applied Microeconomics Seminar Series of the World Bank. www.worldbank.org/en/ events/2016/09/21/demand-for-insurance-under-limited-trust.

Dercon, S., R. Hill, D. Clarke, I. Outes-Leon, and A. Taffesse. 2014. “Offering Rainfall Insurance to Informal Insurance Groups: Evidence from a Field Experiment in Ethiopia.” Journal of Development Economics 106 (January): 132-143.

Elabed, G., and M. R. Carter. 2015. "Compound-Risk Aversion, Ambiguity and the Willingness to Pay for Microinsurance." Journal of Economic Behavior and Organization 118: 150-166.

Farrin, K., and M. Miranda. 2015. “A Heterogeneous Agent Model of Credit-Linked Index Insurance and Farm Technology Adoption." Journal of Development Economics 116: 199-211.

Flatnes, J. E., and M. Carter. 2015. "Fail-Safe Index Insurance without the Cost: A Satellite Based Conditional Audit Approach." Working paper, University of California-Davis.

Gaurav, S., S. Cole, and J. Tobacman. 2011. "Marketing Complex Financial Products in Emerging Markets: Evidence from Rainfall Insurance in India." Journal of Marketing Research 48 (special interdisciplinary issue 2011: Consumer Financial Decision Making): S150-S162.

Giné, X., R. Townsend, and J. Vickery. 2007. "Statistical Analysis of Rainfall Insurance Payouts in Southern India." American Journal of Agricultural Economics 89 (5): 1248-1254.

- 2008. "Patterns of Rainfall Insurance Participation in Rural India." World Bank Economic Review 22 (3): 539-566.

Glauber, J. W. 2013. “The Growth of the Federal Crop Insurance Program, 1990-2011.” American Journal of Agricultural Economics 95 (2): 482-488.

_. 2016. "Crop Insurance and Private Sector Delivery Reassessing the Public-Private Partnership.” Taxpayers for Common Sense. October.

Goodwin, B., and V. H. Smith. 1995. The Economics of Crop Insurance and Disaster Aid. Washington, DC: AEI Press.

Greatrex, H., J. Hansen, S. Garvin, R. Diro, S. Blakeley, M. Le Guen, K. Rao, and D. Osgood. 2015. Scaling Up Index Insurance for Smallholder Farmers: Recent Evidence and Insights. CCAFS Report 14. Copenhagen: CGIAR Research Program on Climate Change, Agriculture and Food Security. 
Hazell, P., J. Anderson, N. Balzer, A. Hastrup Clemmensen, U. Hess, and F. Rispoli. 2010. “The Potential for Scale and Sustainability in Weather Index Insurance for Agriculture and Rural Livelihoods." International Fund for Agricultural Development and World Food Programme, Rome.

Hazell, P., and U. Hess. 2016. Innovations and Emerging Trends in Agricultural Insurance. Bonn: GIZ.

Hellmuth, M. E., D. E. Osgood, U. Hess, A. Moorhead, and H. Bhojwani, eds. 2009. Index Insurance and Climate Risk: Prospects for Development and Disaster Management. Climate and Society No. 2. International Research Institute for Climate and Society (IRI), Columbia University, New York.

Hill, R. V., and M. Robles. 2010. Flexible Insurance for Heterogeneous Farmers: Results from a Small-Scale Pilot in Ethiopia. IFPRI Discussion Paper 1092. Washington, DC: IFPRI.

Hill, R. V., M. Robles, and F. Ceballos. 2016. "Demand for a Simple Weather Insurance Product in India: Theory and Evidence.” American Journal of Agricultural Economics 98: 1250-1270.

Hoddinott, J. 2006. "Shocks and Their Consequences across and within Households in Rural Zimbabwe.” Journal of Development Studies 42: 301-321.

India, Ministry of Agriculture. 2018. Agricultural Statistics at a Glance 2017. Farmers Welfare Department of Agriculture, Cooperation and Farmers Welfare Directorate of Economics and Statistics.

Janzen, S. A., and M. R. Carter. 2019. "After the Drought: The Impact of Microinsurance on Consumption Smoothing and Asset Protection." American Journal of Agricultural Economics $101(3): 651-671$.

Jensen, N., and C. Barrett. 2017. "Agricultural Index Insurance for Development." Applied Economic Perspectives and Policy 39 (2): 199-219.

Jensen, N., C. Barrett, and A. Mude. 2016. "Index Insurance Quality and Basis Risk: Evidence from Northern Kenya." American Journal of Agricultural Economics 98 (5): 1450-1469.

_. 2017. "Index Insurance and Cash Transfers: A Comparative Analysis from Northern Kenya." Journal of Development Economics 129: 14-28.

Jensen, N., A. Mude, and C. Barrett. 2018. "How Basis Risk and Spatiotemporal Adverse Selection Influence Demand for Index Insurance: Evidence from Northern Kenya." Food Policy 74: $172-198$.

Karlan, D., E. Kutsoati, M. McMillan, and C. Udry. 2011. "Crop Price Indemnified Loans for Farmers: A Pilot Experiment in Rural Ghana." Journal of Risk and Insurance 78: 37-55.

Karlan, D., R. Osei, I. Osei-Akoto, and C. Udry. 2014. "Agricultural Decisions after Relaxing Credit and Risk Constraints." Quarterly Journal of Economics 129 (2): 597-652. 
Kramer, B., F. Ceballos, M. Krupoff, M. S. Toor, A. Mishra, S. Karekar, and M. Robles. 2017.

"Picture-Based Insurance: Is It Sustainable? Effects on Willingness to Pay, Adverse Selection, and Moral Hazard." Project Note 2. Washington, DC: IFPRI.

Kyle, E., A. de Janvry, E. Sadoulet, and M. H. Dar. 2016. “Technological Innovations, Downside Risk, and the Modernization of Agriculture." American Economic Review 106 (6): 1537-1561.

Liu, Y., K. Chen, R. Hill, and C. Xiao. 2016. Delayed Premium Payment, Insurance Adoption, and Household Investment in Rural China. IFPRI Discussion Paper 1306. Washington, DC: IFPRI.

Mahul, O., and C. J. Stutley. 2010. Government Support to Agricultural Insurance: Challenges and Options for Developing Countries. Washington, DC: World Bank.

McIntosh, C., F. Povel, and E. Sadoulet. 2019. “Utility, Risk and Demand for Incomplete Insurance: Lab Experiments with Guatemalan Co-Operatives." Economic Journal 129 (August): 2581-2607.

Micro Insurance Center. 2016. The Landscape of Microinsurance Africa 2015: The World Map of Microinsurance. Luxembourg: Microinsurance Network; Bonn: Munich ReFoundation.

Microinsurance Network (n.d.). World Map of Microinsurance. http://worldmapofmicro insurance.org/.

Miranda, M. J., and K. Farrin. 2012. “Index Insurance for Developing Countries." Applied Economic Perspectives and Policy 34 (3): 391-427.

Mobarak, A. M., and M. Rosenzweig. 2012. "Selling Formal Insurance to the Informally Insured.” Working paper 1007, Economic Growth Center, Yale University, New Haven, CT.

Morduch, J. 1995. “Income Smoothing and Consumption Smoothing.” Journal of Economic Perspectives 9 (3): 103-114.

Richardson, A. D., K. Hufkens, T. Milliman et al. 2018. “Tracking Vegetation Phenology across Diverse North American Biomes Using PhenoCam Imagery.” Scientific Data 5: 180028.

Rosenzweig, M., and H. Binswanger. 1993. "Wealth, Weather Risk and the Composition and Profitability of Agricultural Investments.” Economic Journal 103 (416): 56-78.

World Bank. 2005. Managing Agricultural Production Risk Innovations in Developing Countries. Washington, DC: World Bank Agriculture and Rural Development Department.

WFP (World Food Program) and IFAD (International Fund for Agricultural Development). 2010. The Potential for Scale and Sustainability in Weather Index Insurance for Agriculture and Rural Livelihoods. Rome.

Zimmerman, F. J., and M. R. Carter. 2003. "Asset Smoothing, Consumption Smoothing and the Reproduction of Inequality under Risk and Subsistence Constraints." Journal of Development Economics 71 (2): 233-260. 